\title{
Pharmacophore Modelling, Molecular Docking and Virtual Screening for Histamine H1 Receptor Antagonists from Traditional Chinese Medicine
}

\author{
Xing Wang, Zhenzhen Ren, Yuhong Xiang, Yanling Zhang, and Yanjiang Qiao
}

\begin{abstract}
This investigation was performed to identify histamine H1-receptor antagonists from traditional Chinese medicine through virtual screening based on pharmacophore and molecular docking. First, the pharmacophore models were generated though ten known $\mathrm{H} 1$ receptor antagonists. The models were validated by a test database and shown to have good performance in external validation. The best pharmacophore was employed to screen Traditional Chinese Medicine Database, which resulting in a hit list of 421 compounds. Then, the hits were subjected to molecular docking for further refinement. An empirical scoring function was used to evaluate the affinity of the compounds and the target protein. Parts of compounds with high docking scores have been reported to have the related pharmacological activity in the literatures. The findings indicated that virtual screening based on pharmacophore and molecular docking can provide a helpful tool to reveal the active ingredients from Chinese herbs. It can be used for identification of novel $\mathrm{H1}$ antagonists from Traditional Chinese Medicine.
\end{abstract}

Index Terms-Histamine H1-receptor, virtual screening, traditional chinese medicine, active natural ingredients identification.

\section{INTRODUCTION}

Histamine, an ubiquitous chemical messenger that released from a variety of cells, has a key physiological role in the control of gastric acid secretion and allergic disorders. The histamine receptors are a class of $\mathrm{G}$ protein-coupled receptors with histamine as their endogenous ligand [1]-[3]. There are four known histamine receptors: $\mathrm{H} 1, \mathrm{H} 2, \mathrm{H} 3$ and $\mathrm{H} 4$. Histamine mediates allergic and inflammatory responses mainly through histamine $\mathrm{H} 1$ receptors, so $\mathrm{H} 1$ receptor antagonists can provides a highly successful approach to controlling allergic reactions [4], [5]. The first-generation antihistamines, such as diphenhydramine, tripelennamine, chlorpheniramine and promethazine, are able to across the blood-brain barrier. This ability contributes to their main adverse effect of sedation at the same time. So the first-generation are quickly replaced by the second-generation, which are far more selective for

Manuscript received January 15, 2013; revised March 15, 2013. This work was supported by the Foundation of National Natural Science Foundation of China (No. 81173522) and National Key Technology R\&D Program (No. 2008BAI51B01) in Beijing University of Chinese Medicine.

X. Wang, Y. L. Zhang, Z. Z. Ren, and Y. J. Qiao are with the Beijing University of Chinese Medicine, Beijing 100102, China (e-mail: yjqiao@263.net).

Y. H. Xiang is with Capital Normal University, Beijing 100048, China. (e-mail: cnuxiangyh@163.com). peripheral histamine H1-receptors and have fewer side-effects compared to the first-generation agents. But they make people sleepy as well, so discovering novel and safe H1-receptor antagonists is an important task to do.

Traditional Chinese medicine (TCM) is an ancient practice that has been practiced and perfected over thousands of years. It often uses the herbal concoctions, which contain hundreds of compounds from different biosynthetic origin and different chemical scaffolds, to counter the symptoms of diseases. It's an extremely important and difficult work to recognize the active ingredients from hundreds compounds. In this paper, a combined virtual screening based on ligand and structure was proposed to quest for potential $\mathrm{H} 1$ receptor antagonists from TCM. And the hits with high scores were analyzed through literatures.

\section{MATERIALS AND METHODS}

\section{A. Compounds and Biological Data}

Compounds 1 10, which can inhibit H1-receptor, were taken from the literatures [6]-[8] and served as the training set in the pharmacophore modeling. The structures and inhibitory activities of the compounds are listed in Fig. 1. The chemical structures were drawn in ISIS-Draw software and saved in SYBYL mol2 format. All the 2D structures were converted to 3D structures by SYBYL X-1.2 software.

\section{B. Modeling Tool}

The studies were performed with SYBYL X-1.2 package (Tripos Inc., USA) running on Red Hat Linux workstation. The GALAHAD module was used to generate the pharmacophore model of H1 antagonists, the UNITY module was used to perform a flex search for the potential antagonists based on the pharmacophore model and the Surflex-Dock (SFXC) module was used to perform molecular docking.

\section{Pharmacophore Modeling}

Genetic algorithm with linear assignment of hypermolecular alignment of datasets (GALAHAD) was used to generate the pharmacophore models. All the compounds in the training set were prepared by the following procedures: the structures were checked for bond orders, hydrogen atoms were added and a minimization procedure was implemented using the MMFF94 force-field. GALAHAD was run for 100 generations with a population size of 80 . The rest of the parameters were set as default values. The generated models were evaluated by a test 
database which composed 130 experimentally known $\mathrm{H} 1$ antagonists [9]-[21] and 340 non-active compounds picked out from MDL Drug Data Report (MDDR, Version 200712) database.

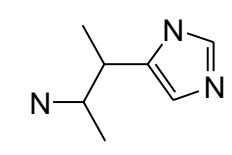

$$
\text { Compound } 1
$$

$$
\left(\mathrm{IC}_{50} 1.3 \mathrm{nM}\right)
$$

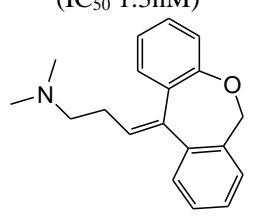

Compound 4

$\left(\mathrm{IC}_{50} 0.003 \mathrm{nM}\right)$

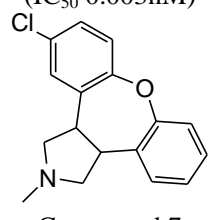

Compound 7

$\left(\mathrm{IC}_{50} 1.9 \mathrm{nM}\right)$

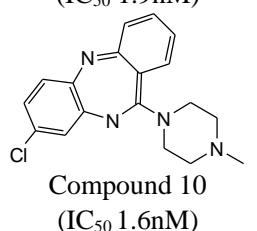

Fig. 1. Chemical structure of H1-receptor antagonists.

\section{Model Evaluation and Virtual Screening}

The pharmacophore models were generated by GALAHAD and validated by the test database, several parameters were employed for model evaluation and calculated as follows:

$$
\begin{gathered}
A \%=\frac{H a}{A} \times 100 \% \\
Y \%=\frac{H a}{H t} \times 100 \% \\
N=\frac{H a \times D}{H t \times A} \\
C A I=N \times A \%
\end{gathered}
$$

$D$ is the total number of compounds in test database and A is the number of active compounds. Ht is the total number of hit compounds from test database and $\mathrm{Ha}$ is the number of active hit compounds from test database. A\% represents the ability to identify active compounds from test database, Y\% represents the proportion of active compounds in the hit compounds. $\mathrm{N}$, the index of effective identification, was used to evaluate the ability of the models to identify active compounds from the non-active compounds. CAI, a comprehensive evaluation index, was used to determine which model is the best model. The model with the highest value of CAI is considered to be the best. The best model was used to screen Traditional Chinese Medicine Database (TCMD,. Version 2009).

\section{E. Molecular Docking Studies}

The crystal structure of histamine $\mathrm{H} 1$ receptor $(\mathrm{H} 1,3.10 \AA$, 3RZE.pdb) was selected as the docking template. The ligand doxepin was extracted, crystallographic water molecules in the structure were removed, hydrogen atoms of modeled structure were added to define the correct configuration and tautomeric states. With the standard parameters, the modeled structure was energy-minimized using AMBER7 F99 force field with the Powell energy minimization algorithm, distance dependent dielectric function and current charges.

After extracting the binding ligand, the structure of $\mathrm{H} 1$ receptor was used for re-docking with doxepin, and the docking score was calculated to check the accuracy of the Surflex-Dock program. The default parameters, as implemented in the SYBYL X-1.2 software, were used.

The compounds hit by the pharmacophore generated were automatically docked into the binding site of $\mathrm{H} 1$ successively. A protomol-based method and an empirically derived scoring function was used to calculate the interaction of the ligands and $\mathrm{H} 1$ receptor. The scoring function includes hydrophobic, polar, repulsive, entropic, solvation and crash terms. High total score implies good binding capacity. The crash value represents the degree of inappropriate penetration by the ligand into the protein and of interpenetration (self-clash) between ligand atoms that are separated by rotatable bonds. A smaller crash value indicates a better ability to exclude the false positives screened. Polar represents the contribution of the polar interactions to the total score. The polar score is useful for excluding docking results that make no hydrogen bonds.

\section{RESULTS AND DISCUSSION}

\section{A. Pharmacophore Modelling}

Twenty GALAHAD models, generated by ten known H1 antagonists, were derived from more than seven ligands. Model 3, 9, 14, 19 and 20 had high energy $\left(S E>1.0 \times 10^{8}\right)$, which is considered to be due to steric clashes, leading to their exclusion from the analysis. The other 15 models were evaluated successively by the test database constructed previously. Table I shows the predictable results for each model. Model_017, with the highest value of CAI, was considered to be the best model.

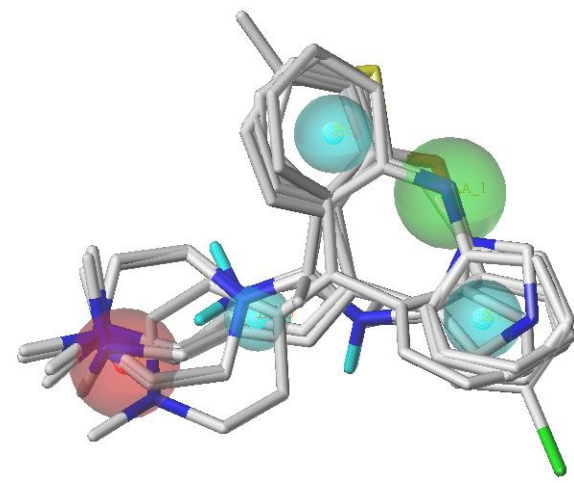

Fig. 2. Pharmacophore model_017 and molecular alignment of the compounds. 
The pharmacophore features of Model_017 were displayed in Fig. 2, where cyan, green and magenta spheres indicate hydrophobes, $\mathrm{HB}$ acceptors and $\mathrm{HB}$ donors, respectively. Model_017 includes five pharmacophore features: three hydrophobes, one HB acceptors and one HB donors.

TABLE I: THE PARAMETER VALUES FOR EACH PHARMACOPHORE MODEL

\begin{tabular}{ccccccc}
\hline \hline Model & Ht & Ha & A\% & Y\% & N & CAI \\
\hline 1 & 347 & 126 & 0.97 & 0.36 & 1.31 & 1.27 \\
2 & 340 & 126 & 0.97 & 0.37 & 1.34 & 1.30 \\
4 & 332 & 126 & 0.97 & 0.38 & 1.37 & 1.33 \\
5 & 328 & 126 & 0.97 & 0.38 & 1.39 & 1.35 \\
6 & 292 & 87 & 0.67 & 0.30 & 1.08 & 0.72 \\
7 & 80 & 29 & 0.22 & 0.36 & 1.31 & 0.29 \\
8 & 97 & 32 & 0.25 & 0.33 & 1.19 & 0.29 \\
10 & 80 & 34 & 0.26 & 0.43 & 1.54 & 0.40 \\
11 & 145 & 75 & 0.58 & 0.52 & 1.87 & 1.08 \\
12 & 360 & 126 & 0.97 & 0.35 & 1.27 & 1.23 \\
13 & 158 & 98 & 0.75 & 0.62 & 2.24 & 1.69 \\
15 & 213 & 114 & 0.88 & 0.54 & 1.93 & 1.70 \\
16 & 265 & 86 & 0.66 & 0.32 & 1.17 & 0.78 \\
17 & 154 & 97 & 0.75 & 0.63 & 2.28 & 1.70 \\
18 & 352 & 126 & 0.97 & 0.36 & 1.29 & 1.25 \\
\hline \hline
\end{tabular}

\section{B. Virtual Screening}

Model_017 was used to screen TCMD, which contains 23033 natural chemical compositions. A query fit (QFIT) value was computed for each hit to rank the matching rate of its required structural features on the pharmacophoric query, a high QFIT score corresponds to a good alignment between pharmacophore model and compound conformer. Virtual screening based on pharmacophore was performed resulting in a hit list of 421 compounds. According to the QFIT values, the top 20 compounds are listed in Table II, and the best compounds mapping on Model_017 are shown in Fig. 3.Then, the compounds were subjected to molecular docking for further refinement.

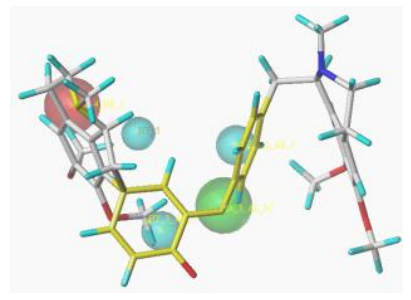

a)

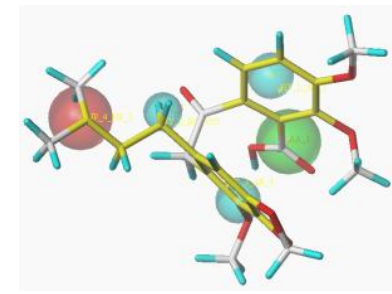

b)
Fig. 3. Model_017 mapped with a) Pakistanamine and b) Pseudocarpaine.

\section{Molecular Docking}

All the hits were docked into the active site of $\mathrm{H} 1$ receptor. The docking reliability was validated by re-docking the ligand extracted and the structure of $\mathrm{H} 1$ receptor. The low root mean-square deviation (RMSD) of $0.56 \AA$ between the docked and the crystal conformation of doxepin indicated the high reliability of Surflex-dock in reproducing the experimentally observed binding mode for $\mathrm{H} 1$ inhibitor.

TABLE II: THE TOP 20 COMPOUNDS HIT BY PHARMACOPHORE MODEL_017

\begin{tabular}{|c|c|c|c|c|}
\hline No & בID & Q QFIT & " name & source plant \\
\hline 1 & 16537 & 72.5 & Pakistanamine & $\begin{array}{c}\text { Berberis calliobotrys and Berberis } \\
\text { julianae }\end{array}$ \\
\hline 2 & 3218 & 61.21 & Pseudocarpaine & Carica papaya. \\
\hline 3 & 18022 & 61.21 & Carpaine & Carica papaya. \\
\hline 4 & 11640 & 60.93 & Isopyruthaldine & Isopyrum thalictroides \\
\hline 5 & 20933 & 60.27 & Tenuicausine & Melodinus tenuicaudatus. \\
\hline 6 & 19592 & 58.93 & Scutianine D & Scutia buxifolia \\
\hline 7 & 21269 & 58.07 & Thalrugosidine & Thalictrum alpinum \\
\hline 8 & 12861 & 56.74 & Lindechunine B & Lindera chunii \\
\hline 9 & 648 & 56.4 & Adouetine $\mathrm{X}$ & Waltheria americana. \\
\hline 10 & 2456 & 56.2 & $\begin{array}{c}\text { '2',6'-Bis(p-hydroxybenzyl)-3,3'- } \\
\text { dihydroxy-5-methoxybibenzyl }\end{array}$ & Gymnadenia conopsea \\
\hline 11 & 3882 & 54.47 & Cocsuline & Cocculus pendulus. \\
\hline 12 & 22596 & 54.22 & Voacamine & family Apocynaceae spp. \\
\hline 13 & 2106 & 53.83 & Baicalin & Scutellaria baicalensis \\
\hline 14 & 5099 & 52.87 & De-O-methyltenuicausine & Melodinus hemsleyanus. \\
\hline 15 & 14410 & 52.54 & O-12'-Methyl ergocornine & Claviceps purpurea. \\
\hline 16 & 12564 & 52.44 & Launobine & Lindera umbellata and Laurus nobilis \\
\hline 17 & 21244 & 52.24 & Thalicrine & Thalictrum thunbergii \\
\hline 18 & 9444 & 50.73 & Hernandine & Lindera chunii \\
\hline 19 & 6315 & 49.84 & Giraldine G & Delphinium giraldii \\
\hline 20 & 2102 & 49.56 & Baicalein & Scutellaria baicalensis \\
\hline
\end{tabular}

The compounds hit by pharmacophore model were docked into the active pocket of $\mathrm{H} 1$ receptor successively. The docking score was calculated by an empirically derived scoring function that is based on the binding affinities of protein-ligand complexes. 24 compounds with high docking scores were shown in Table III. The interactions between 
Baicalin and active site of $\mathrm{H} 1$ receptor is shown in Fig. 4.

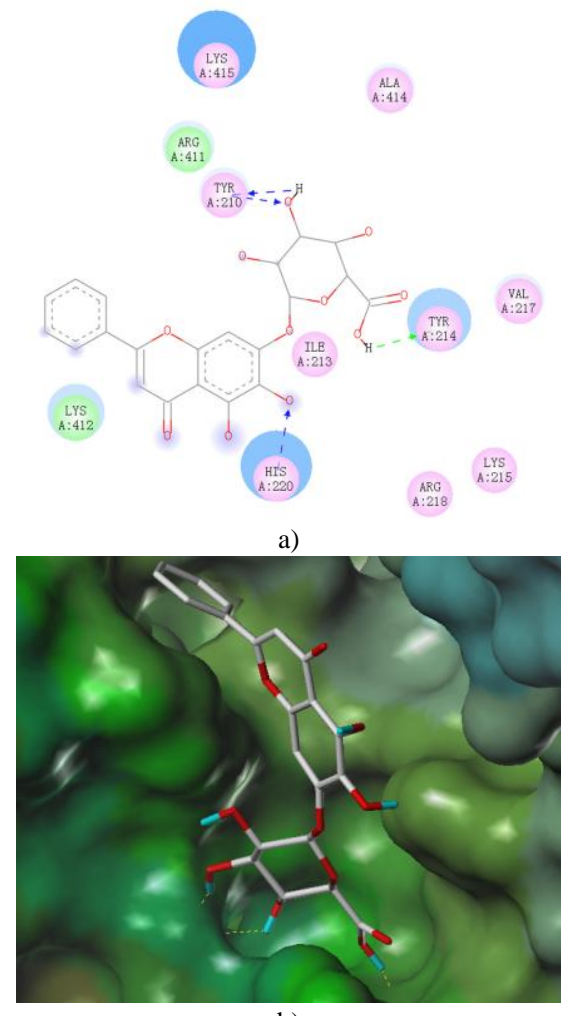

b)

Fig. 4. The interactions between Baicalin and active site of $\mathrm{H} 1$ receptor. Key residues are displayed and hydrogen bonds are displayed in dotted lines. a) $2 \mathrm{D}$ concise schematic diagram of the interactions between Baicalin and $\mathrm{H} 1$ receptor. b) MOLCAD lipophilic potential surface of the binding pockets with the docked compound Baicalin.

TABLE III: THE DOCKING RESULTS TO H1 RECEPTOR

\begin{tabular}{cccc}
\hline \hline Name & Total_Score & Crash & Polar \\
\hline 9102 & 10.173 & -1.3262 & 0.0003 \\
12683 & 9.5702 & -3.3676 & 2.6081 \\
12891 & 9.5168 & -1.7739 & 2.0805 \\
5905 & 7.9974 & -3.5484 & 2.4087 \\
14154 & 7.5825 & -1.1533 & 1.0442 \\
18790 & 7.1964 & -1.069 & 2.9856 \\
23 & 7.1412 & -1.2142 & 0.0139 \\
2106 & 7.1296 & -3.6908 & 3.1928 \\
4417 & 6.9752 & -0.7217 & 0.9007 \\
16268 & 6.9716 & -4.3417 & 1.1258 \\
2165 & 6.8233 & -0.6496 & 1.288 \\
9100 & 6.4317 & -4.0569 & 2.7437 \\
1838 & 6.374 & -2.3313 & 1.044 \\
14995 & 6.2569 & -6.9532 & 2.4127 \\
6853 & 6.146 & -0.7035 & 1.2522 \\
1836 & 5.856 & -1.8147 & 0.8967 \\
13137 & 5.5521 & -1.3155 & 2.9342 \\
7054 & 5.433 & -14.1886 & 0.0086 \\
21356 & 5.394 & -1.125 & 3.3838 \\
2102 & 5.2989 & -1.0127 & 2.406 \\
5722 & 5.2721 & -1.3506 & 0.0001 \\
12767 & 5.265 & -1.3465 & 2.1881 \\
16525 & 5.1705 & -14.9457 & 0.1384 \\
1837 & 5.0351 & -2.6299 & 1.1922 \\
\hline \hline
\end{tabular}

\section{Top Scoring Compounds}

As evident from the virtual screening, the pharmacophore was carried out resulting in a hit list of 421 compounds, and the docking studies showed that 24 compounds with high docking scores have good binding capacity with histamine H1-receptor. Parts of the compounds have been reported to have the pharmacological activity related to $\mathrm{H} 1$ receptor inhibition by literatures. Lin found that Baicalein (ID 2102) and Baicalin (ID 2106) extracted from Scutellaria rivularis have the anti-inflammatory activity against carrageenan-induced paw edema in rats [22]. Cortisone (ID 6853 ) and cuscohygrine (ID 1836) were discovered to have the active of anti-allergy [23], [24]. Matsuda found that Batatasin III (ID 2165), 2',6'-Bis-3,3'-dihydroxy-5methoxybibenzyl (ID 2456), Gymconopin A (ID 9099) and Gymconopin B(ID 9100) extracted from the tubers of Gymnadenia conopsea had an antiallergic effect on ear passive cutaneous anaphylaxis reactions in mice [25]. To a certain extent, the calculation and screening results may provide an explanation for the pharmacological effects of the plant herbs. However, the results need further experiments to confirm.

\section{CONCLUSIONS AND FUtURE WORK}

In this paper, the computational method based on pharmacophore, molecular docking and virtual screening was established to quest for $\mathrm{H} 1$ receptor antagonists from Traditional Chinese herbs. The pharmacophore model established was used to identify the common features of $\mathrm{H} 1$ receptor antagonists from known active compounds. And molecular docking was employed to study the detailed binding mode between the ligand and active site of $\mathrm{H} 1$ receptor. The computational approaches showed the advantage in saving time and resources. It's feasible to quest for $\mathrm{H} 1$ receptor antagonists from Traditional Chinese herbs by using virtual screening based on pharmacophore and molecular docking. Several active compounds were identified from the structurally diverse mixture in traditional Chinese medicine. Thus, it revealed an available tool to quest for $\mathrm{H} 1$ receptor antagonists by virtual screening. It can also be used in other targets, not limtied to $\mathrm{H} 1$ receptor. In the following study, the compounds hit by pharmacophore model and molecular docking need further verification using related biological experiments, this will help to find effective $\mathrm{H} 1$ receptor antagonists and lead compounds from Traditional Chinese medicine.

\section{ACKNOWLEDGEMENT}

This work was financially supported by the Foundation of National Natural Science Foundation of China (No. 81173522) and National Key Technology R\&D Program (No. 2008BAI51B01) in Beijing University of Chinese Medicine.

\section{REFERENCES}

[1] A. S. Ash and H. O. Schild, "Receptors mediating some actions of histamine," Br J Pharmacol Chemother, vol. 27, pp. 427-439, Aug. 1966.

[2] S. J. Hill, C. R. Ganellin, H. Timmerman, J. C. Schwartz, N. P. Shankley, J. M. Young, W. Schunack, and R. Levi, H. L. Haas, 
"International Union of Pharmacology. XIII. Classification of histamine receptors," Pharmacol Rev, vol. 49, pp. 253-278, September 1997.

[3] M. E. Parsons and C. R. Ganellin, "Histamine and its receptors," $\mathrm{Br} J$ Pharmacol, vol. 147, pp. 127-135, January 2006.

[4] R. Leurs, M. K. Church, and M. Taglialatela, "H1-antihistamines: inverse agonism, anti-inflammatory actions and cardiac effects," Clin Exp Allergy, vol. 32, pp. 489-498, April 2002.

[5] R. Leurs, M. J. Smit, and H. Timmerman, "Molecular pharmacological aspects of histamine receptors," Pharmacol Ther, vol. 66, pp. 413-463, June 1995.

[6] K. Kubota, H. Kurebayashi, H. Miyachi, M. Tobe, M. Onishi, and Y. Isobe, "Synthesis and structure-activity relationships of phenothiazine carboxylic acids having pyrimidine-dione as novel histamine $\mathrm{H}(1$ antagonists," Bioorg Med Chem Lett, vol. 19, pp. 2766-2771, May 2009.

[7] K. Kubota, H. Kurebayashi, H. Miyachi, M. Tobe, M. Onishi, and Y Isobe, "Synthesis and structure-activity relationship of tricyclic carboxylic acids as novel anti-histamines," Bioorg Med Chem, vol. 79, pp. 3005-3021, May 2011.

[8] C. Quinones-Torrelo, S. Sagrado, R. M. Villanueva-Camanas, and M. J. Medina-Hernandez, "Development of predictive retention-activity relationship models of tricyclic antidepressants by micellar liquid chromatography," J Med Chem, vol. 42, pp. 3154-3162, Aug. 1999.

[9] M. Abou-Gharbia, J. A. Moyer, S. T. Nielsen, M. Webb, and U. Patel, "New antihistamines: substituted piperazine and piperidine derivatives as novel H1-antagonists," J Med Chem, vol. 38, pp. 4026-4032, Sep. 1995.

[10] N. C. Becknell, J. A. Lyons, L. D. Aimone, J. A. Gruner, J. R Mathiasen, R. Raddatz, and R. L. Hudkins, "Synthesis and evaluation of pyridone-phenoxypropyl-R-2-methylpyrrolidine analogues as histamine H3 receptor antagonists," Bioorg Med Chem Lett, vol. 21, pp 7076-7080, Dec. 2011

[11] G. Campiani, S. Butini, S. Gemma, V. Nacci, C. Fattorusso, B. Catalanotti, G. Giorgi, A. Cagnotto, M. Goegan, T. Mennini, P. Minetti, M. A. Di Cesare, D. Mastroianni, N. Scafetta, B. Galletti, M. A. Stasi, M. Castorina, L. Pacifici, O. Ghirardi, O. Tinti, and P. Carminati, "Pyrrolo[1,3]benzothiazepine-based atypical antipsychotic agents. Synthesis, structure-activity relationship, molecular modeling, and biological studies," J Med Chem, vol. 45, pp. 344-359, Jan. 2002.

[12] T. Coon, W. J. Moree, B. Li, J. Yu, S. Zamani-Kord, S. Malany, M. A. Santos, L. M. Hernandez, R. E. Petroski, A. Sun, J. Wen, S. Sullivan, J. Haelewyn, M. Hedrick, S. J. Hoare, M. J. Bradbury, P. D. Crowe, and G. Beaton, "Brain-penetrating 2-aminobenzimidazole H(1)-antihistamines for the treatment of insomnia," Bioorg Med Chem Lett, vol. 19, pp. 4380-4384, Aug. 2009

[13] S. Fonquerna, M. Miralpeix, L. Pages, C. Puig, A. Cardus, F. Anton, A. Cardenas, D. Vilella, M. Aparici, E. Calaf, J. Prieto, J. Gras, J. M. Huerta, G. Warrellow, J. Beleta, and H. Ryder, "Synthesis and structure-activity relationships of novel histamine H1 antagonists: indolylpiperidinyl benzoic acid derivatives," J Med Chem, vol. 47, pp. 6326-6337, Dec. 2004

[14] S. Hayashi, E. Nakata, A. Morita, K. Mizuno, K. Yamamura, A. Kato, and K. Ohashi, "Discovery of $\{1-[4-(2-\{$ hexahydropyrrolo [3,4-c]pyrrol $\quad-2(1 \mathrm{H})-\mathrm{yl}\}-1 \quad$ H-benzimidazol-1-yl) piperidin-1-yl]cyclooctyl\} methanol, systemically potent novel non-peptide agonist of nociceptin/orphanin FQ receptor as analgesic for the treatment of neuropathic pain: design, synthesis, and structure-activity relationships," Bioorg Med Chem, vol. 18, pp. 7675-7699, Nov. 2010.

[15] W. J. Moree, B. F. Li, F. Jovic, T. Coon, J. Yu, R. S. Gross, F. Tucci, D. Marinkovic, S. Zamani-Kord, S. Malany, M. J. Bradbury, L. M Hernandez, Z. O'Brien, J. Wen, H. Wang, S. R. Hoare, R. E. Petroski, A Sacaan, A. Madan, P. D. Crowe, and G. Beaton, "Characterization of novel selective H1-antihistamines for clinical evaluation in the treatment of insomnia," J Med Chem, vol. 52, pp. 5307-5310, Sep. 2009.

[16] D. E. Nichols, S. Frescas, D. Marona-Lewicka, and D. M Kurrasch-Orbaugh, "Lysergamides of isomeric 2,4-dimethylazetidines map the binding orientation of the diethylamide moiety in the potent hallucinogenic agent N,N-diethyllysergamide (LSD)," J Med Chem, vol. 45, pp. 4344-4349, Sep. 2002.

[17] G. Semple, T. A. Tran, B. Kramer, D. Hsu, S. Han, J. Choi, P. Vallar, M. D. Casper, N. Zou, E. K. Hauser, W. Thomsen, K. Whelan, D. Sengupta M. Morgan, Y. Sekiguchi, K. Kanuma, S. Chaki, and A. J. Grottick, "Pyrimidine-based antagonists of h-MCH-R1 derived from ATC0175: in vitro profiling and in vivo evaluation," Bioorg Med Chem Lett, vol. 19, pp. 6166-6171, Nov. 2009.
[18] M. C. Sleevi, A. D. Cale Jr., T. W. Gero, L. W. Jaques, W. J. Welstead, A. F. Johnson, B. F. Kilpatrick, I. Demian, J. C. Nolan, and H. Jenkins, "Optical isomers of rocastine and close analogues: synthesis and H1 antihistaminic activity of its enantiomers and their structural relationship to the classical antihistamines," J Med Chem, vol. 34, pp. 1314-1328, Apr. 1991.

[19] T. Ulven, T. M. Frimurer, J. M. Receveur, P. B. Little, O. Rist, P. K. Norregaard, and T. Hogberg, "6-Acylamino-2-aminoquinolines as potent melanin-concentrating hormone 1 receptor antagonists. Identification, structure-activity relationship, and investigation of binding mode," J Med Chem, vol. 48, pp. 5684-5697, Sep. 2005.

[20] D. A. Walsh, S. K. Franzyshen, and J. M. Yanni, "Synthesis and antiallergy activity 4-(diarylhydroxymethyl)-1-[3-(aryloxy)propyl]piperidines and structurally related compounds," J Med Chem, vol. 32, pp. 105-118, Jan. 1989.

[21] Y. Yan, Q. Zhong, N. Zhao, and G. Liu, "First cascade Mitsunobu reactions for the synthesis of 2-benzoxazole-N-phenyl and 2-benzimidazole-N-phenyl derivatives," Mol Divers, vol. 16, pp. 157-162, Feb. 2012.

[22] C. C. Lin and D. E. Shieh, "The anti-inflammatory activity of Scutellaria rivularis extracts and its active components, baicalin, baicalein and wogonin," Am J Chin Med, vol. 24, pp. 31-36, 1996

[23] A. Narayanasamy and M. Narayanasamy, "Ayurvedic medicine: An introduction for nurses," Br J Nurs, vol. 15, pp. 1185-1190, Nov. 2006.

[24] M. Simonsen, "On the effect of cortisone on allergy and complement titer," Scand J Clin Lab Invest, vol. 2, pp. 287-291, 1950.

[25] H. Matsuda, T. Morikawa, H. Xie, and M. Yoshikawa, "Antiallergic phenanthrenes and stilbenes from the tubers of Gymnadenia conopsea," Planta Med, vol. 70, pp. 847-855, Sep. 2004.

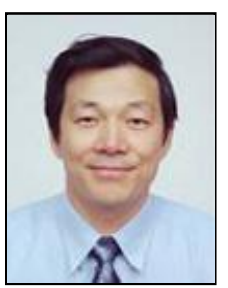

Yanjiang Qiao was born in Shandong Province, China, in 1956. He graduated from the Department of Pharmaceutical Analysis of Shen-Yang Pharmaceutical University and gained Ph.D in 1997. Having study in USA, Canada as a visiting scholar and in Beijing University of Chinese Medicine as a post-doctorial researcher. His major field of study is the TCM information Engineering.

His scientific research directions include Information Technology for Active Compounds Discovery, Information Technology for Combination Rules Discovery, and Information Techniques for Quality control of the TCM production process. His published articles: NIR analysis for batch process of ethanol precipitation coupled with a new calibration model updating strategy, A Novel Model Selection Strategy Using Total Error Concept, Solubilization of saikosaponin a by ginsenoside Ro biosurfactant in aqueous solution:Mesoscopic simulation.

Prof. Yan-Jiang Qiao is an advisor of Ph.D candidates in the field of TCM Informatics and Quality Control. He is the deputy principal of Beijing University of Chinese Medicine; Member of the 5th Discipline Evaluation Group (Chinese Medicine and Chinese materia medica) of Academic Degrees Committee of the State Council; Member of Committee of Experts of Chinese Pharmacological and Natural Pharmacological Society of Chinese Pharmacological Society; Chairman of Chinese Pharmaceutical Analysis Society of China Association of Traditional Chinese Medicine Vice Chairman of Professional Committee for Chinese Pharmacy Digitalization of China Information Association For Traditional Chinese Medicine and Pharmacy; Vice Chairman of Doctor Academic Research Association of China Association of Traditional Chinese Medicine; Chairman of "Beijing Key Laboratory for Basic and Developmental Research on Chinese Medicine"; Editorial Board Member of World Science and Technology: Modernization of Traditional Chinese Medicine, Chinese Journal of Pharmaceutical Analysis, Chinese Journal of Natural Medicines and Journal of Beijing University of Traditional Chinese Medicine.

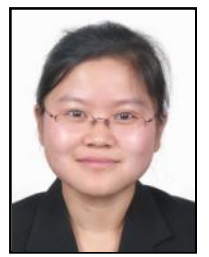

Yanling Zhang was born in Anhui Province, China, in 1980. She graduated from the College of Chinese Pharmacology in Beijing University of Chinese Medicine and gaind Ph.D in 2006. His major field of study is the TCM information Engineering.

She is now an associate professor in Beijing University of Chinese Medicine. Her research mainly focuses on the computer aided drug design and pharmacoinformatics, which is funded by National Natural Science Fund of China, China Postdoctoral Science Foundation and major program of State Key Development Program for Basic Research of China. More than 30 scientific papers have been published. 


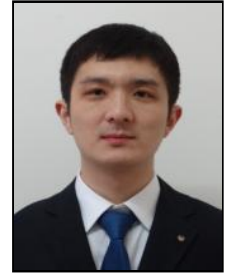

Xing Wang was born in Henan Province, China in 1983. He graduated from the College of Pharmacy in Henan University of Traditional Chinese Medicine and gained Master's degree in 2009. His major field of study is the TCM information Engineering.

$\mathrm{He}$ is now working on his $\mathrm{PhD}$ in Beijing University of Chinese Medicine focusing on "Active Compounds and Mechanism of action Discovery in TCM". During the school period, he has published seven research papers and won the National Scholarship. The partly published articles include: Rational questing for Inhibitors of ECE-1 from Salvia miltiorrhiza by combining ligand and structure based virtual screening, Rapid analysis of Fructus forsythiae by near-infrared spectroscopy, Application of pharmacophore technique in the study of TCM.

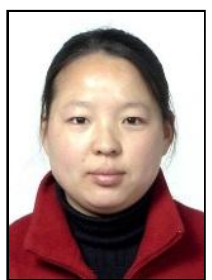

Yuhong Xiang was born in Hebei Province, China, in 1976. She graduated from the University of Science and Technology of China and gained Ph.D in 2005. Her major field of study is analytical chemistry.

She is now an associate professor in capital normal university. Her research mainly focuses on the computer aided drug design. More than 30 scientific papers have been published. The partly published articles include: Pharmacophore and QSAR studies to design nove histone deacetylase 2 inhibitors. A novel two-step QSAR modeling work flow to predict selectivity and activity of HDAC inhibitors.

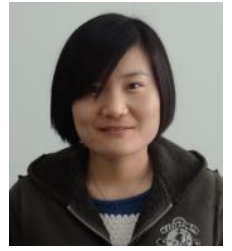

Zhenzhen Ren was born in Hebei Province, China, in 1985. Zhenzhen Ren graduated from the Chengde Medical College and gaind Bachelor of Science degree in 2011. Now she is studing at the Traditional Chinese Medicine College in Beijing University of Chinese Medicine for the Master's degree. Her major field of study is TCM design and optimization.

She is now a master degree candidate in Beijing University of Chinese Medicine and she has won the scholarship of school. Her scientific research directions is biological network-based design and optimization of Traditional Chinese Medicine. As a participant she has published articles include: Pharmacophore Model Generation of thrombin Inhibitors, Rational questing for Inhibitors of ECE-1 fromSalvia miltiorrhizaby combining ligand andstructure based virtual screening. 